\title{
A Case of Severe Tricuspid Stenosis of Rheumatic Origin
}

\author{
MT Rahman, M Das, M Ullah, Z Rahman, A Hossain, LA Sayami, SS Roy, AAS Majumder \\ Department of Cardiology, National Institute of Cardiovascular Disease, Dhaka, Bangladesh.
}

\begin{abstract}
Keywords:
Tricuspid

stenosis;

Rheumatic heart

disease; Valvular

heart disease.
\end{abstract}

\begin{abstract}
:
Tricuspid valve stenosis is a valvular heart disease which results in the narrowing of the orifice of the tricuspid valve of the heart. It's relatively a rare condition. It is almost always caused by rheumatic fever and is generally accompanied by mitral stenosis.Other rare causes include carcinoid syndrome, endocarditis, endomyocardial fibrosis, lupus erythematosus, right atrial myxoma and congenital tricuspid atresia. Here we describe a patient with history of prior CMC presented with severe Tricuspid Stenosis with Tricuspid Regurgitation (Grade-IV), Mitral Restenosis (Severe), Mitral Regurgitation (grade-1+), Aortic Stenosis (Mild) and Aortic Regurgitation (Grade-2).
\end{abstract}

(Cardiovasc. j. 2011; 3(2): 235-238)

\section{Introduction:}

Tricuspid valve stenosis is a valvular heart disease which results in the narrowing of the orifice of the tricuspid valve of the heart. It's relatively a rare condition. The stenosis causes increased resistance to blood flow through the valve. It is almost always caused by rheumatic fever and is generally accompanied by mitral stenosis.Rare other causes include carcinoid syndrome, endocarditis, endomyocardial fibrosis, lupus erythematosus, right atrial myxoma and congenital tricuspid atresia. $^{1-9}$

The mortality associated with tricuspid stenosis depends on the precipitating cause. The general mortality rate is approximately $5 \%{ }^{1}$

Tricuspid stenosis is found in approximately $3 \%$ of the international population. It is more prevalent in areas with a high incidence of rheumatic fever. The congenital form of the disease is rare and true incidence is not available. ${ }^{1,2}$

Tricuspid stenosis can present as a congenital lesion or later in life when it is due to some other condition. The congenital form accounts for approximately $0.3 \%$ of all congenital heart disease cases. The frequency of tricuspid stenosis in the older population, due to secondary causes, ranges from $0.3-3.2 \%{ }^{2}$

Tricuspid stenosis is observed more commonly in women than in men, similar to mitral stenosis of rheumatic origin. The congenital form of the disease has a slightly higher male predominance. ${ }^{2}$

Tricuspid valve stenosis itself usually doesn't require treatment. However, if there is damage to other valves in the heart as well, then surgical repair or replacement must be considered.The treatment is usually by surgery (tricuspid valve replacement) or percutaneous balloon valvuloplasty. The resultant tricuspid regurgitation from percutaneous treatment is better tolerated than insufficiency occurring during mitral valvuloplasty. ${ }^{1-3}$

Here we describe a patient with history of prior Closed Mitral Commissurotomy (CMC) presented with severe Tricuspid Stenosis with Tricuspid Regurgitation (Grade-IV), Mitral Restenosis (Severe), Mitral Regurgitation (Grade-1+), Aortic Stenosis (Mild) and Aortic Regurgitation (Grade-2).

\section{Case History:}

Mrs. X, a 34 years old housewife, admitted into NICVD, with the complaints of exertional shortness of breath for last 11 years and shortness of breath on lying flat for last 2 years. She also complained of recurrent swelling of both lower limbs and distension of abdomen that was occasionally relieved by intravenous diuretics. She was diagnosed as a case of chronic rheumatic heart disease with severe mitral stenosis and underwent CMC in 1993 when he was only 15 years old. After

Address of Correspondence- Dr. Md. Toufiqur Rahman , Associate Professor, Department of Cardiology , NICVD, Dhaka, Bangladesh. 
doing CMC she was reasonably well for the next 8 years.

On examination, patient was ill looking, orthopnoeic, mildly anaemic, edematous, mildly icteric, not cyanosed. Her neck vein was engorged. Pulse rate was $80 \mathrm{~b} / \mathrm{min}$, irregularly irregular with pulsus deficit of 16 beats/ min. B.P. was 80/60 $\mathrm{mmHg}$. Apex is shifted $2 \mathrm{~cm}$ lateral to left midclavicular line and left parasternal heave was present. First heart sound was variable, P2 was palpable. There was a mid diastolic murmur, grade-3/6 over apical area and a ejection systolic murmur over right second intercostal space and a diastolic murmur over left lower sternal border having grade of $3 / 6$. Breath sound was vesicular and there was bilateral basal crepitations. There was tense ascites and tender hepatomegaly. On careful Echo Doppler examination, patient had Tricuspid Stenosis (Severe) with Tricuspid Regurgitation (Grade-IV), Mitral Stenosis (Severe), Mitral Regurgitation (grade-1+), Aortic Stenosis (Mild) and Aortic Regurgitation (Grade-2) (Fig$1,2,3)$. She was treated conservatively.

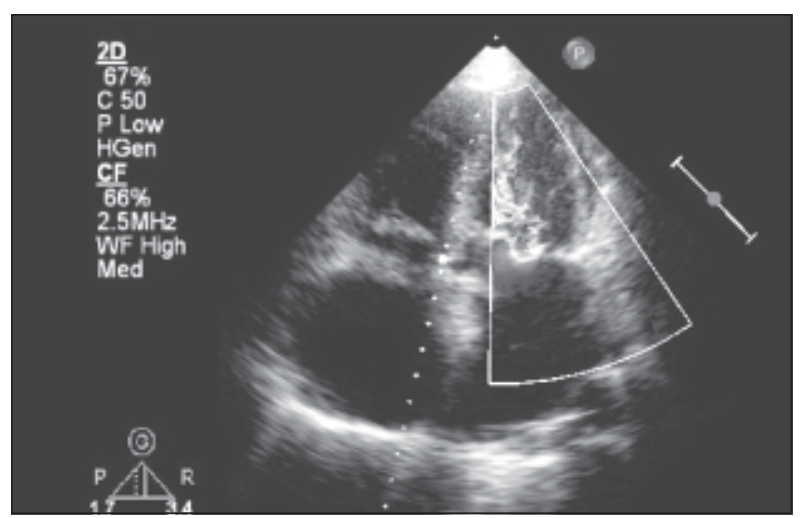

Fig.-1: Mitral stenosis

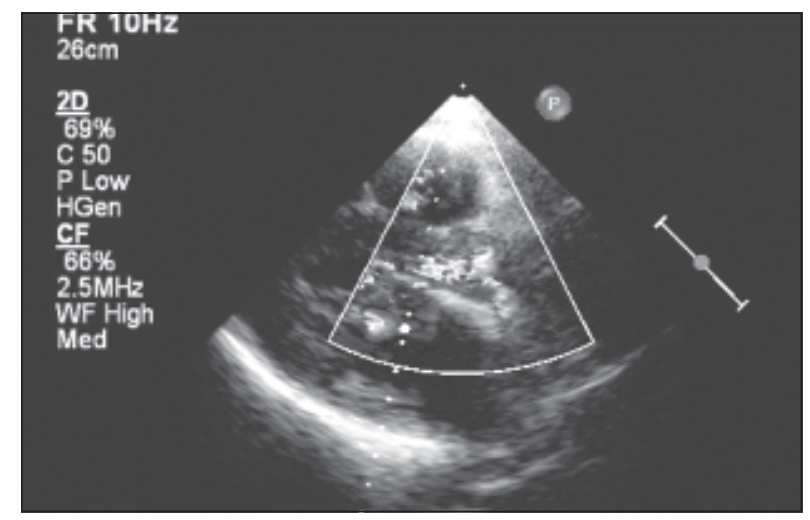

Fig.-2: Aortic regurgitation

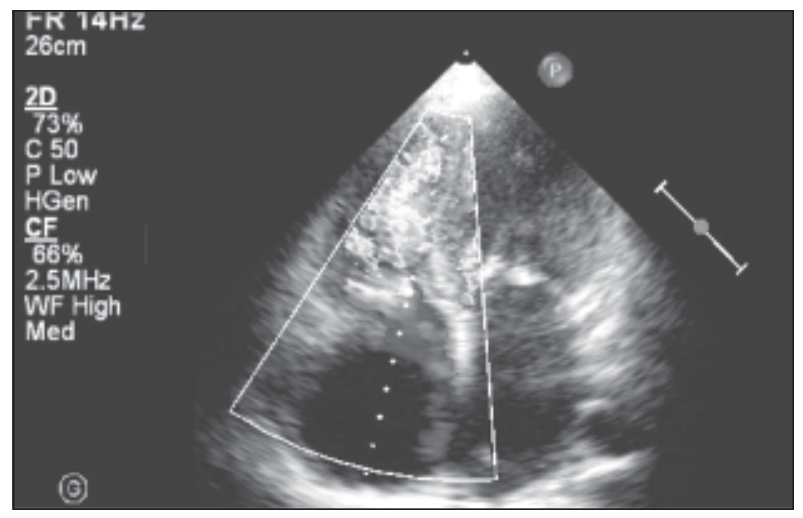

Fig.-3: Tricuspid Stenosis

\section{Discussion:}

Tricuspid valve dysfunction can result from morphological alterations in the valve or from functional aberrations of the myocardium. Tricuspid stenosis is almost always rheumatic in origin and is generally accompanied by mitral and aortic valve involvement. ${ }^{1}$

Most stenotic tricuspid valves are associated with clinical evidence of regurgitation that can be documented by performing a physical examination (murmur), echocardiography, or angiography. Stenotic tricuspid valves are always anatomically abnormal, and the cause is limited to a few conditions. With the exceptions of congenital causes or active infective endocarditis, tricuspid stenosis takes years to develop. ${ }^{2,3}$

Sato $\mathrm{M}$ et al described a case of tricuspid stenosis found intraoperatively during aortic valve replacement and open mitral commissurotomy with congestive heart failure due to mitral regurgitation and tricuspid regurgitation and so, commissurotomy and modified Kay's annuloplasty was tried but failed to decrease the central regurgitation. A CarboMedics $23 \mathrm{~mm}$ prosthesis was implanted in the mitral position and a Capentier-Edwards $29 \mathrm{~mm}$ in the tricuspid position. ${ }^{10}$

Tsutomu Saito ${ }^{11}$ et al reported the case of a 42 year-old man in whom dyspnea on exertion was found to be caused by isolated tricuspid stenosis. Two-dimensional echocardiogram showed thickening of the tricuspid valve with a markedly enlarged right atrium. A color-flow Doppler examination-revealed severe tricuspid stenosis without regurgitation and a Doppler-derived 
tricuspid diastolic pressure gradient of $23 \mathrm{mmHg}$. At the time of surgery, the patient was noted to have a stenotic tricuspid valve with thickened leaflets, fused commissures, and almost normal chorda tendineae. The valve leaflets were teased apart to the scattered specimen, and tricuspid valve replacement was successfully performed. Microscopic examination of the specimen demonstrated infective endocarditis. Isolated acquired tricuspid stenosis is extremely rare and that was the first case of infective endocarditis being involved as the primary cause.

Yash Y et al reported a patient with congenital tricuspid stenosis successfully treated by percutaneous balloon valvotomy that appears to be an alternative to surgery when the anatomy, as demonstrated by echocardiography, is suitable. ${ }^{12}$

Taira Kayano et $a^{13}$ reported Tricuspid Valve Stenosis Related to Subvalvular Adhesion of Pacemaker Lead An excessive loop of a ventricular lead, especially a subvalvular loop, can cause opening limitation of the tricuspid valve, and the entangling of the lead in the subvalvular structures can easily induce reactive fibrosis and adhesions.

Hussain et al described a case tricuspid stenosis in a young woman 11 years after endocardial ventricular lead implantation. The cause of the stenosis was perforation of the septal leaflet by the lead at the time of insertion and then successful management with percutaneous balloon valvuloplasty without the need for lead removal. ${ }^{14}$

Ashraf et al reported a case of concurrent successful percutaneous valvuloplasty of combined mitral and tricuspid value stenosis employing the Inoue technique. ${ }^{15} \mathrm{D}$ J Heaven et $\mathrm{al}^{16}$ described two cases of pacemaker lead related tricuspid stenosis. Sivert Svane reported six autopsied cases of Congenital Tricuspid Stenosis ${ }^{17}$.M E Lee et al reported a case of unusual complications of endocardial pacing like simultaneous thrombosis of the superior and inferior venae cavae and supravalvular, valvular, and infravalvular stenosis of the tricuspid valve. ${ }^{18} \mathrm{~L}$ G Van der Hauwaert et al ${ }^{19}$ reported a case of fibroma of the right ventricle producing severe tricuspid stenosis.

Roguin et $\mathrm{al}^{20}$ reported Long-term follow-up of patients with severe rheumatic tricuspid stenosis.
13 patients (11 women and 2 men) with severe tricuspid stenosis who were followed closely for 6 to 31 years. The mean tricuspid pressure gradient ranged from 3 to $9 \mathrm{~mm} \mathrm{Hg}$. Twelve patients underwent surgery for mitral and/or aortic valve lesions without complications. Concomitant tricuspid valve surgery was performed on six patients. After successful repair of the mitral or aortic valve, and regardless of the type of tricuspid valve surgery, severe tricuspid stenosis was found to be very well tolerated by all the patients over many years of follow-up. L V Basso et al reported a case of Tricuspid valve obstruction due to intravenous leiomyomatosis. ${ }^{21}$

\section{References:}

1. Waller BF. Morphological aspects of valvular heart disease: Part I. Curr Probl Cardiol 1984;9(7):1-66.

2. Waller BF. Morphological aspects of valvular heart disease: Part II. Curr Probl Cardiol 1984;9(8):1-74.

3. Morgan JR, Forker AD, Coates JR, Myers WS. Isolated tricuspid stenosis. Circulation 1971;44(4):729-32.

4. Mukhopadhyay S, Suryavanshi S, Yusuf J, et al. Isolated thrombus producing tricuspid stenosis: an unusual presentation in primary antiphospholipid syndrome. Indian Heart $J$ 2004;56(1):61-3.

5. Sakata Y, Koibuchi N, Xiang F, et al. The spectrum of cardiovascular anomalies in $\mathrm{CHF} 1 / \mathrm{Hey} 2$ deficient mice reveals roles in endocardial cushion, myocardial and vascular maturation. J Mol Cell Cardiol 2005; 18.

6. Sharieff S, Saghir T, Shah-e-Zaman K, et al. Concurrent percutaneous valvuloplasty of mitral and tricuspid valve stenoses. J Invasive Cardiol 2005;17(6):340-2.

7. DiSesa VJ, Mills RM Jr, Collins JJ Jr. Surgical management of carcinoid heart disease. Chest 1985;88(5):789-91.

8. Kratz JM, Crawford FA Jr, Stroud MR, et al. Trends and results in tricuspid valve surgery. Chest 1985;88(6):837-40.

9. Miller BR, Vohr FH, Christian FV, Singh AK. Cardiac valvular replacement in carcinoid heart disease. $\mathrm{Am} \mathrm{J}$ Med 1983;75(5):896-8.

10. Sato M, Ito J, Hayashibe Y, Goto K, Maemura T, Konno $\mathrm{S}$, Sekiya T. A case report of tricuspid replacement for the acquired tricuspid stenosis at the time of reoperation. Kyobu Geka 1994 ;47(5):398-400.

11. Tsutomu Saito, Hiroyuki Horimi, Tsuguo Hasegawa, Toshiro Kamoshida. Isolated tricuspid valve stenosis caused by infective endocarditis in an adult: Report of a case. Surgery Today 1993; 23(12):1081-1084.

12. Yash Y. Lokhandwala, Rajesh M. Rajani, Bharat V. Dalvi and Purshottam A. Successful balloon valvotomy in isolated congenital tricuspid stenosis . CardioVascular and Interventional Radiology, Springer New York 1990; 13( 6):354-356. 
13. Taira Kayano,Suzuki Asumi, Fujino Akihisa, Watanabe Tatsuya, Ogyu Atsuhiro, Ashikawa Kouichi .Tricuspid Valve Stenosis Related to Subvalvular Adhesion of Pacemaker Lead: A Case Report. J Cardiol 2006; .47(6):301-306.

14. Tarique Hussain, William Brodie Knight and Karen A. McLeod, Lead-Induced Tricuspid Stenosis-Successful Management by Balloon Angioplasty. Pacing and Clinical Electrophysiology 2009;32,(1), 140-142.

15. Tariq Ashraf, Asad Pathan, Asadullah Kundi. Percutaneous Balloon Valvuloplasty of Coexisting Mitral and Tricuspid Stenosis: Single-Wire, Double-Balloon Technique. J Invasive Cardiol 2008;20:E126-E128.

16. D J Heaven, M Y Henein, R Sutton. Pacemaker lead related tricuspid stenosis: a report of two cases. Am Heart J 1998 ;136 (1):103-8.
17. Sivert Svane. Congenital Tricuspid Stenosis:A Report on Six Autopsied Cases Scandinavian Cardiovascular Journal 1971;5(3): 232-238.

18. M E Lee, A Chaux Unusual complications of endocardial pacing. Clin Cardiol 1995 ;18 (3):167-74.

19. L G Van der Hauwaert, L Corbeel, P Maldague Fibroma of the right ventricle producing severe tricuspid stenosis. Heart 2000 ;83 (3):351-2.

20. A Roguin, D Rinkevich, S Milo, W Markiewicz, S A Reisner Long-term follow-up of patients with severe rheumatic tricuspid stenosis. Am Heart J 1998 ;136 (1):103-8.

21. L V Basso, M Gradman, S Finkelstein, L GonzalezLavin Tricuspid valve obstruction due to intravenous leiomyomatosis. Curr Probl Cardiol 1984 ;9 (8):1-74. 